\title{
Expresión artística del cuerpo para mujeres con fibromialgia
}

\author{
Silvana PARENTE COSTA ${ }^{1}$ \\ Universidad de Granada \\ silvanaparente@yahoo.com.br
}

Recibido: $30 / 13 / 13$

Aceptado: 06/12/13

\begin{abstract}
RESUMEN
La arteterapia / fibromialgia es una metodología creada para mujeres con fibromialgia con la intención de ayudar en la mejora de su imagen corporal y el descubrimiento de potencialidades expresivas. Forma parte de un doctorado del curso de Ciencia de la Educación de la Universidad de Granada. En él realizamos talleres con veintidós mujeres con fibromialgia, con edades comprendidas entre los 40 y los 70 años, utilizando la danza, el vídeo, las artes escénicas y la escritura. El análisis del trabajo ha sido hecho por medio de las escrituras y del vídeo del proceso, obteniendo comprensión de la enfermedad y descubriendo las potencialidades de movimientos y expresiones.
\end{abstract}

Palabras clave: Danza, dolor, fibromialgia, autoimagen, cuerpo, artes escénicas, estatua, arteterapia, expresividad, imagen corporal, danza, vídeo, escritura, terapia.

\section{Referencia normalizada}

PARENTE COSTA, S. (2013). "Expresión artística del cuerpo para mujeres con fibromialgia". En Arteterapia: Papeles de arteterapia y educación artística para la inclusión social Vol.: 8. Páginas 61-70.

\section{SUMARIO}

Introducción. Arteterapia. Fibromialgia: conceptualización y estado de la encuesta. Metodología. Materiales artísticos utilizados. Resultados. Conclusión.

\section{Artistic expression of the body to fibromyalgia women}

\begin{abstract}
Art therapy / fibromyalgia is a methodology created for women with fibromyalgia with the intention to assist in the improvement of their body image and the discovery of expressive potential. Form part of a doctorate of science education at the University of Granada. In the we do workshops with twenty-two women with fibromyalgia, between the ages of 40 and 70 years, using dance, video, performing arts and writing. The analysis of the work has been done through the Scriptures and of the video of the process, gaining understanding of the disease and discovering the potential of movements and expressions.
\end{abstract}

\footnotetext{
${ }^{1}$ Silvana Parente es actriz (Universidade de Fortaleza, Brasil), bailarina(Escuela de Ballet Clasico Madyana Romcy), comunicóloga social(Faculdades do Nordeste, Brasil) y arteterapeuta(Faculdade Paulista de Artes, Brasil). Recibió formación en Brasil y trabaja con expresión corporal hace once años, tanto en obras de teatro como en el ámbito terapéutico. Actualmente hace doctorado en la Universidad de Granada.
} 
Keywords: Dance, pain, fibromyalgia, self, body, performing arts, sculpture, art therapy, expressiveness, body image, dance, video, writing, therapy.

\section{CONTENTS}

Introduction. Art Therapy. Fibromyalgia: conceptualization. Methodology. Art materials used. Results. Conclusion.

\section{INTRODUCCIÓN}

El presente artículo forma parte de una investigación iniciada en 2010 en el marco del doctorado de la Universidad de Granada en la Facultad de Bellas Artes y Ciencias de la Educación. La investigación tiene como antecedentes otros estudios realizados en Brasil desde 2008.

Aquí mostraré un breve historial de los motivos de investigar las intervenciones arteterapéuticas en el diagnostico de la fibromialgia, que empezó en Brasil. Después explicaré lo que son la arteterapia y la fibromialgia, así como los objetivos, metodología, métodos y resultados de la investigación desarrollada en el doctorado.

La investigadora lleva seis años estudiando e investigando la intervención de la expresión artística del cuerpo para mujeres con fibromialgia con diferentes enfoques. Comenzó en 2008 con el trabajo final de su curso de formación de Arteterapia en la Facultad Paulista de Artes, pasando por el grupo interdisciplinar del ambulatorio de fibromialgia de la clínica médica de la facultad de medicina de la Universidad de de São Paulo, hasta llegar al doctorado en la Universidad de Granada. Eso ha hecho ampliar el proceso de elección de las técnicas utilizadas con la intención de hacer más efectiva la intervención arteterapéutica de la investigación aquí expuesta.

El trabajo de fin de curso de Arteterapia fue un estudio teórico sobre la arteterapia y la fibromialgia, planteando la posibilidad de crear una intervención con elementos artísticos para ese tipo de enfermedad. Y la conclusión ha sido que por tratarse de una enfermedad sintomatológica, o sea, se realiza mediante criterios clínicos que son tomados de la historia de los síntomas de pacientes y los hallazgos a la exploración física, que se debe realizar de forma adecuada. ${ }^{2}$ Además, la arteterapia puede mejorar la vida de los pacientes con fibromialgia. Porque, como afirma Naumburg, la arteterapia es una técnica que se puede aplicar con personas de todas las edades afectadas por diferentes patologías. Puede ser una forma primaria de psicoterapia o un tratamiento auxiliar o adicional a otros tratamientos psicológicos o psiquiátricos. Yo añadiría que hoy en día, para hacer arteterapia, ni siquiera se precisa estar enfermo o padecer de una psicopatología concreta,

2 Antonio Collado Cruz (1990) ¿Qué es la fibromialgia?, Barcelona, disponible en http://www.parcdesalutmar.cat/mar/Fibromialgia.pdf pg.16 
puesto que se puede iniciar una arteterapia con el fin de saber más sobre uno mismo, con miras a un crecimiento personal o para desarrollar y potenciar la creatividad. $^{3}$

La utilización de la arteterapia para el diagnóstico de personas con fibromialgia auguraba un trabajo próspero y que merece ser investigado.

A continuación de ese trabajo hice otro en el Hospital de las Clínicas de la facultad de Medicina de la Universidad de São Paulo, como parte del grupo de tratamiento alternativo del ambulatorio de fibromialgia. En él observamos, por medio de talleres construidos con la ayuda de la directora del ambulatorio, Lais Verdame Lage, que con sesiones compuestas de estiramientos, baile libre y juegos de estatua se ayudaba a que las pacientes durmieran mejor, tuvieran más auto-confianza dentro de hogar y se sintieran relajadas. Eso fue testimoniado en citas médicas pos taller.

Con esas experiencias desarrollé un plan de investigación para ser desarrollado en España en forma de doctorado. A continuación expondré la experiencia que me han aportado los talleres realizados con mujeres de las asociaciones de fibromialgia de Campillos de Málaga y Guadix, Andalucía (España).

\section{ARTETERAPIA}

Las definiciones de arteterapia son numerosas, y una de ellas consiste en considerarla un proceso terapéutico proveniente de la utilización del arte. Para el psicoanalista Winnicott, autor clave para la arteterapia, el proceso creador es una área de "experiencias" que media entre las realidades internas y externas del individuo.4 Así, se consigue que el arte sea un "puente" para unir estas informaciones.

La trayectoria de la arteterapia se inició de forma paralela en Estados Unidos y Reino Unido. Durante la década de los treinta hasta los años sesenta, el arteterapia comienza a construir su propia autonomía disciplinar, nutriéndose de gran afluencia de enfoques pero, al mismo tiempo, desvinculando progresivamente su práctica de la educación artística, la terapia ocupacional y del papel reduccionista otorgado a las actividades plásticas, tanto en los diagnósticos psiquiátricos como en las psicoterapias verbales. 5

$\mathrm{La}$ arteterapia es una terapia que se ocupa del uso del lenguaje artístico. Tiene como base la sensibilización del paciente por medio de los materiales artísticos, por lo tanto entra en contacto con las sensaciones y las transformaciones esbozadas en su obra de arte, en la cual habrá elementos de su estado emocional incons-

\footnotetext{
${ }^{3}$ Eva Marxen (2011): Diálogos entre arte y terapia, Barcelona, editoral Gedeisa, p. 33.

${ }^{4}$ López Fernández Cao, M. y Martínez Díez, N. (2006): Arteterapia: Conocimiento interior a través de la expresión artística. Madrid, Ediciones Tutor, p. 22.

${ }^{5}$ López Martínez, M $\mathrm{M}^{\mathrm{a}} \mathrm{D}$. (2009): La intervención arteterapéutica y su metodología en el contexto profesional español (tesis doctoral). 115-116.
} 
ciente y actual. Jung, en la década de los 20, utilizó el arte como parte del tratamiento con sus pacientes. Él consideraba el material artístico y las imágenes de los sueños como representación del inconsciente individual y colectivo. Estudió y observó símbolos de muchas culturas y mitologías, con eso juntó aspectos similares y creó el concepto del arquetípico. Esto es un concepto hipotético postulado por él para explicar la manifestación de imágenes arquetípicas, o sea, todas las imágenes que aparecen en sueños y fantasías, y que según él guardan notable similitud con temáticas universales encontradas en la religión, los mitos y leyendas, etc. 6

Con estos elementos simbolizados en el material artístico producido por el paciente, descubriremos lo que aflige a este paciente. Esa información forma parte del proceso terapéutico del arte. Y el trabajo del arteterapeuta consiste en intervenir también con las herramientas artísticas necesarias para el tratamiento de ese paciente, no solo en descubrir lo que le aflige.

\section{LA FIBROMIALGIA}

La explicación que haré aquí sobre lo que es la fibromialgia será corta, no profundizaré, pero intentaré acercar al lector de este articulo a la comprensión de la enfermedad, ya que esta es de difícil diagnóstico y pasó por cambios del Colegio Americano de Reumatología (ACR).

En 2010 cambió el criterio que se había usado los años anteriores. Aproximadamente el $25 \%$ de los pacientes con fibromialgia no satisfacían los criterios de clasificación de 1990 del Colegio Americano de Reumatología (ACR). En el mes de mayo de 2010, el ACR publicó unos criterios simples y prácticos para el diagnóstico clínico de la fibromialgia, aptos para su uso en la atención primaria y en la especializada, que no requieren un examen de puntos sensibles y que proporcionan una escala de gravedad (EG) para los síntomas característicos de la fibromialgia. Esta simple definición del caso clínico de fibromialgia clasifica correctamente el $88,1 \%$ de los casos clasificados por los criterios de clasificación del ACR, y no requiere un examen físico o de puntos sensibles. La escala EG permite la valoración de la gravedad de los síntomas de la fibromialgia en personas con fibromialgia actual o previa y en las personas en las que los criterios todavía no han sido aplicados. Será especialmente útil en la evaluación longitudinal de pacientes con una marcada variabilidad sintomática7.

\footnotetext{
${ }^{6}$ Afonso Valadares, A. C. (2003): Arteterapia com Crianças hospitalizadas, Ribeirão Preto São Paulo, disertação de mestrado, p.43.

${ }^{7}$ Wolfe F, Clauw DJ, Fitzcharles MA, Goldenberg DL, Katz RS, Mease P, Russell AS, Russell IJ, Winfield JB, Yunus MB. (2010): Criterios preliminaresde diagnóstico del Colegio Americano de Reumatología para la fibromialgia y para la medición de la gravedad de su síntomas. Reivindi-
} 
Con ellos es conveniente realizar una anamnesis de los factores psicológicos y psiquiátricos: antecedentes personales y familiares de trastorno mental; sintomatología psicopatológica actual y nivel de apoyo social, incluyendo las relaciones familiares y la repercusión y/o condiciones en la esfera sociolaboral. En general, el paciente fibromiálgico presenta síntomas depresivos. Ciertamente, los factores psicosociales influyen en la gravedad de los síntomas que, debido a un mecanismo de retroalimentación, producen incapacidad funcional y alteraciones psicológicas, afectan en grados variables y suelen impedir el funcionamiento rutinario del sujeto8. Es de mucha importancia que el paciente con fibromialgia conozca su cuerpo y posibilidades, porque con eso tiene la herramienta para administrar el dolor descubriendo posibilidades de él.

\section{OBJETIVO}

Esta investigación tuvo como objetivo crear una intervención para hacer que las pacientes piensen, reaccionen y descubran su imagen corporal de manera renovada y rehabilitadora, conociendo sus potencialidades por medio de la actividad creadora y de auto observación que la mezcla de los elementos artísticos elegidos ofrece. La técnica utilizada es en grupo y con sesiones ya estructuradas.

Analizamos, por medio de los materiales artísticos, los límites terapéuticos de la expresión artística a través del cuerpo en mujeres con fibromialgia, con la intención de saber si esta intervención puede aliviar el dolor, mejorar la calidad de vida y favorecer la imagen corporal de estas pacientes.

En este aspecto, la intervención es la herramienta para que ellas tomen conciencia de sí mismas y de sus cuerpos, pues son ellas mismas las que sacan sus conclusiones acerca de cómo convivir con la enfermedad y encontrar nuevas posibilidades de vivir bien con sus cuerpos.

El fin es hacer que las pacientes piensen, reaccionen y descubran su imagen corporal de manera renovada y rehabilitada. En efecto, descubrieron sus potencialidades por medio de la actividad creadora y de auto-observación que la mezcla de los elementos artísticos elegidos ofrece.

cación de derechos. Articulo original: arthrits care \& research, Vol. 62, nº 5, mayo de 2010.Estados Unidos

${ }^{8}$ Maeda, C., Martínez, J. y Nedser, M. (2006): Efeito da Eutonia no Tratamento da Fibromialgia. Revista Brasileira de Reumatología, ene-feb 2006, p.4. Brasil 


\section{METODOLOGÍA}

La técnica utilizada ha sido en grupo y con sesiones ya programadas, seis sesiones a lo largo de tres semanas. Las sesiones están compuestas por vídeo, danza y escritura.

La fundamentación teórica de base utiliza sobre todo dos referencias. Por un lado, conceptos de la Teoría de la Danza y la Educación en Movimiento de Ángel Vianna, que defiende el lenguaje corporal como herramienta de autoconocimiento, y por otro la Danza Movimiento Terapia (DMT) estudiada por Hilda Wengrower. La DMT pone el acento en el cuerpo y su postura, en la forma en que esta influye en la percepción de uno mismo y de los otros. El conocimiento del cuerpo debería ser parte del contexto educacional y servir de aprendizaje de nosotros mismos para que, de forma natural, nos sirviera para reconocernos y como alerta para cuidarnos. Eso es prevención. Es un proceso de conocimiento, construcción, organización y elaboración que repercute en una estructuración del lenguaje del cuerpo, medio primordial de comunicación.

El reclutamiento de las mujeres con fibromialgia ha sido hecho en asociaciones de fibromialgia. La AFPOM (Asociación de Fibromialgia y Problemas Óseos y Musculares de Campillos de Málaga) y la Asociación de Fibromialgia y Síndrome de Fatiga Crónica: Manejo de las enfermedades de Guadix. Los talleres se realizaron en junio de 2011 en Campillos de Málaga con doce participantes y en julio de 2012 en Guadix con diez participantes.

Las seis sesiones fueron desarrolladas a lo largo de tres semanas, con una cámara grabando todo el proceso, que se componía de unas declaraciones delante de la cámara en la primera sesión, para que ellas hablasen sobre su enfermedad, seguido de sesiones de danza con estiramientos, danza libre con y sin música y juegos de estatuas con presentaciones de escena. En la última sesión miramos todos juntos las declaraciones del primer día y la danza, después ellas escribían todo lo que habían aprendido en el taller.

\section{MATERIALES ARTÍSTICOS UTILIZADOS Vídeo}

La utilización de vídeo respondió a la intención de que ellas hablaran ante la cámara al principio de las sesiones contestando preguntas como las siguientes: ¿Cuánto tiempo hace que tienes la enfermedad? ¿Qué haces en tu rutina para ti? y también para que posteriormente pudieran ver los ejercicios realizados. El hecho de pedir que ellas hablasen delante de la cámara, se debió a mi observación de sus cuerpos en el ambulatorio de la facultad de Brasil citada anteriormente. Así, se conseguía que dejaran de estar agobiadas y comenzaba un proceso de autoconocimiento: en esa charla recordaban o descubrían dónde habían comenzado los dolores o desde cuándo ellas priorizaban sus asuntos en su rutina diaria.

El vídeo también es la herramienta que sirve para que ellas entiendan el proceso de desarrollo de sus cuerpos, por eso las sesiones son grabadas y mostradas 
al final. Esta herramienta de filmar a las pacientes en su proceso de baile ya se mostró efectivo en el trabajo de investigación en el Acta Universitatis upsaliensis upplasa de Eva Bonjner Horowitz. ${ }^{9}$

\section{Danza}

La danza tiene la intención de ayudar a las pacientes a descubrir las posibilidades de expresión que su propio cuerpo tiene, empezando un proceso de autodescubrimiento y consecuentemente autoconocimiento. La apliqué como movimientos libres del cuerpo, pidiendo a las mujeres que movieran el cuerpo como quisieran, con y sin música. Esto facilitaba el proceso de exteriorización de las emociones y la comunicación.

\section{Juego de la estatua}

Las estatuas sirven para que las pacientes observen las sensaciones que pasan por su cuerpo y las posibilidades de razonar con el cuerpo inmóvil. Les pido que bailen libremente y, en el momento en el que damos una palmada, deben quedarse estáticas. En ese mismo momento corto la música. Después de aproximadamente un minuto, otra palmada indica que vuelvan a bailar. Este proceso sirve para que ellas elaboren los movimientos y para que organicen sensaciones. Y cuando están inmóviles, observan la expresión del movimiento hecho. Al final de cada sesión, crean una escena individualmente. Pues como dice Constantin Stanislavski en la construcción del personaje, «abran los oídos a sus emociones, que vibran, se agitan, aceleran y remueven en su interior. Ocultas en estos movimientos invisibles hay todo tipo de pulsaciones rápidas y lentas, o sea, tiempos y ritmos.» ${ }^{10}$

\section{Expresión escrita}

Al final, en la última sesión, las pacientes hacen una redacción sobre el vídeo del proceso vivido en el taller. El vídeo contiene las declaraciones del primer encuentro y un montaje de las sesiones que incluye danza y artes escénicas. La escritura sirve para que las pacientes visualicen la toma de conciencia de sí mismas y de sus cuerpos. Son ellas mismas las que sacan sus conclusiones acerca de cómo conviven con la enfermedad y cómo pueden encontrar nuevas posibilidades de vivir bien con sus cuerpos.

\footnotetext{
${ }^{9}$ Bonjner Horowitz, E. (2004): Disertación Dance/Movement Therapy in Fibromyalgia Patients: Aspects and Consequences of Verbal, Visual and Hormonal Analyses. Suecia.

10 Stanislavski, C. (2007). La construcción del personaje, p. 243. Madrid. Alianza Editorial, S.A.
} 


\section{RESULTADOS OBTENIDOS}

Al principio, las pacientes parecían vergonzosas y tímidas, hasta para situarse delante de la cámara. Pero después de que la primera paciente acabara la entrevista para la cámara, el resto se animó a hablar también. Esta acción de hablar delante de la cámara sobre su vida y su enfermedad sirvió para tranquilizar el agobio que habitualmente mostraban. Sus expresiones eran tristes, llenas de suspiros y pausas, con momentos serios y sonrisas discretas.

Todas sin excepción se sorprenden cuando se les formula la pregunta de en qué momento de su rutina empiezan a hacer algo por sí mismas, pues describen solamente sus actitudes hacia los demás. Las pacientes se dan cuenta de lo que han vivido en su entorno familiar y social, observando lo que conseguían hacer antes y ahora no. Así se dan cuenta de que el proceso de dolor, empezó cuando ellas se olvidaran de sí mismas. Porque la otra pregunta, que les hace pensar cuanto tiempo hace que tienen la enfermedad, ayuda en ese proceso, teniendo lugar la constatación de que la enfermedad es una señal de alerta para que empiecen a atender a su cuerpo, su vida y sus necesidades.

En las sesiones de danza, en el primer momento ellas sienten un poco de dolor. Muchas quedan mareadas y piden una pausa. Se explica que esta incomodidad inicial es parte del proceso y que tienen la libertad de parar cuando quieran. Pero ninguna de ellas eligió parar, lo que demostraba sus ganas de superarse.

En las estatuas, ellas pasan por un proceso de autoobservación y elaboración de movimientos y espontáneamente logran movimientos expansivos, lo que hizo que cambiasen informaciones entre ellas sobre las estatuas hechas. Una compañera ayudaba a la otra a recordar las estatuas y a crear escenas para esas estatuas. Se observa con eso que sus cuerpos estaban actuando activamente para un juego artístico, donde el dolor ya no se percibía más. Pusimos el foco en las posibilidades de movimiento que ellas podían hacer allí.

En la última sesión, cuando ellas miraban todo lo que se había hecho, hubo un proceso de reflexión muy grande. Hicimos que ellas expresasen verbalmente y de forma escrita la importancia de observarse, y que describieran cómo el primer día estaban muy serias y después, en las siguientes sesiones, van logrando nuevos movimientos y acciones expresivas. Les pongo aquí algunos fragmentos de los escritos para cerrar los resultados con las declaraciones de algunos testigos:

"En vídeo me veo muy gesticuladora, pienso que muevo mucho los ojos, el cuello y toda la cara. Bueno, la terapia fue estupenda para conocer nuestro cuerpo, que los tenemos olvidados: solo pensamos que nos duele. Tenemos que pensar más en él, en la relajación, respirar bien y cuidar de nuestros cuerpos para sentirnos mejor." M.G.J., 61 años.

"Ha sido una experiencia grata de conocimiento más afectivo hacia otras personas que solo conocíamos de paso. El hecho de expresarnos ante nuestros cono- 
cidos y mirarnos a los ojos hace que la persona interna que guardo dentro salga a la luz, y con el baile deja a la vez apartada las inhibiciones." D.V.O., 52 años.

\section{CONCLUSIÓN}

Se va estableciendo la idea de que no podemos descartar el cuerpo como fuente de información y de curación ni como lugar de manifestación de la enfermedad, no solo física. Sus posturas, su movimiento y el modo de ocupar el espacio nos hablan analógicamente y simbólicamente de tensiones, emociones, relaciones e historias. 11

Concluyo que la mezcla de las modalidades artísticas ha servido como forma gradual de hacer que las mujeres con fibromialgia descubriesen sus actitudes consigo mismas y consecuentemente con su enfermedad. Pasaron por el proceso de desahogo con las respuestas a las preguntas del video, de descontracción y logros de movimientos expresivos y sin dolor, hasta llegar a la constatación de estos logros con el visionado del vídeo. Y la prueba escrita sirve para ayudar a dejar claro para ellas todo el proceso vivido en el taller.

\section{REFERENCIAS BIBLIOGRÁFICAS}

COLLADO, A. (1990) ¿Qué es la fibromialgia?, Barcelona, disponible en http://www.parcdesalutmar.cat/mar/Fibromialgia.pdf pg.16

BONJNER HOROWITZ, E. (2004): Disertación Dance/Movement Therapy in Fibromyalgia Patients: Aspects and Consequences of Verbal, Visual and Hormonal Analyses. Suecia.

LÓPEZ M, M ${ }^{\mathrm{a}}$ D. (2009): La intervención arteterapéutica y su metodología en el contexto profesional español (tesis doctoral). 115-116.

LÓPEZ F, C, M. y Martínez Díez, N. (2006): Arteterapia: Conocimiento interior a través de la expresión artística. Madrid, Ediciones Tutor, p. 22.

MAEDA, C., MARTIÉZ, J. y NEDSER, M. (2006): Efeito da Eutonia no Tratamento da Fibromialgia. Revista Brasileira de Reumatología, ene-feb 2006, p.4. Brasil

MARXEN,E (2011): Diálogos entre arte y terapia, Barcelona, editoral Gedeisa, p. 33.

${ }^{11}$ Wengrower, H. y Chaiklin, S. (2010): La vida es danza, p. 19. Barcelona, Editorial Gedisa. 
MEASE P. RUSEULL, A.S. RUSEULL, I.J. WINFIELD, J.B. YUNUS, M.B. (2010): Criterios preliminaresde diagnóstico del Colegio Americano de Reumatología para la fibromialgia y para la medición de la gravedad de su síntomas. Reivindicación de derechos. Articulo original: arthrits care \& research, Vol. 62, $\mathrm{n}^{\mathrm{o}} 5$, mayo de 2010.Estados Unidos

STANISLAVISKI, C. (2007). La construcción del personaje, p. 243. Madrid. Alianza Editorial, S.A.

WOLFE, F. CLAUW, DJ. FITZCHARLES, MA. GOLDENBERG DL. KATZ, R.S. 